\title{
Cost analysis of rice milling: a case study of 7 rice mills in Malaysia
}

\begin{abstract}
Purpose - The purpose of this paper is to examine the long-run profitability of rice milling operation in Malaysia and see how sensitive it is to changes in paddy purchases, rice recovery ratio and paddy price.
\end{abstract}

Design/methodology/approach - Using a purposive sampling technique and semi-structured interviews, seven rice mills in Malaysia were selected to obtain data on operational details and business accounts. The paper provides a qualitative and descriptive account of the rice mill's profitability by using cost curves, a simple linear regression and the Monte Carlo simulation.

Findings - The rice milling operation in Malaysia is profitable in the long run, provided that there is a market for by-products. Large private mills have lower average costs, helping them obtain higher profit margins. Public mills that receive a rice miller subsidy are more protected than small private mills that operate without the rice miller subsidy and under price controls. Changes in paddy purchases, paddy price and recovery ratio affect the profitability to varying degrees.

Research limitations/implications - Incomplete information provided by the interviewees. The analysis result is only a rough estimate. However, it may provide a useful insight into the Malaysian rice milling sector and its competitiveness.

Originality/value - There are few economic studies of the rice milling sector in Malaysia. However, it plays an important role along the rice supply chain. There is a need for better understanding of the industry in order to obtain economic sustainability and effective policies. This paper provides the gap by providing an insight into the long-run profitability of rice milling operation in Malaysia.

Keyword: Malaysia; Profitability; Sensitivity analysis; Economic sustainability; Rice processing; Price controls; Rice milling 